\title{
THE RELATION OF THE LATERAL LINE ORGANS OF NECTURUS TO HEARING
}

\author{
W. J. PAUL DYE
}

Zoological Laboratory, University of Wisconsin

Among senses hearing is quite unusual. It is restricted to comparatively few groups of animals, and those possessing it are highly organized members of their groups. The Arthropods and vertebrates seem to be the only animals that can really hear; all others probably live in silence. The ear is an unusually perfect mechanism, even excelling the eye. An untrained human ear is able to distinguish between two musical tones struck simultaneously, but the eye is not able to distinguish the various colors that make up "white" light and is easily deceived by blends and mixtures.

The ears of aquatic vertebrates are on the whole less efficient than those of birds and mammals. However, fishes, amphibian tadpoles, and adult aquatic salamanders have accessory organs for perceiving vibratory stimuli which the more specialized vertebrates lack. These are the lateral line organs. In fishes the auditory apparatus is rather simple, consisting of an "inner" ear, imbedded in the skull, and the lateral line organs. Parker (1903-1911) has demonstrated that a fish's ear is sensitive to sounds and that the lateral line also serves as an accessory organ of hearing, responding to vibrations of low rate.

Though aquatic amphibians possess lateral line organs, their reactions to sounds have not been studied. This paper describes experiments which were carried out in order to test the function of the lateral line organs of the mudpuppy in relation to slow vibrations in water.

Following the methods used by Parker (1905), a wire cage was suspended from the ceiling so that it hung partly in the water 
of a large aquarium. On one side of the aquarium a wire was stretched so that it could be made to vibrate at a low rate- 120 times or less per second. There was no opportunity for vibrations which originated on the floor or sides of the aquarium to be communicated to a mudpuppy in the cage, except through water.

Two types of mudpuppies were tested: (1) normal individuals and (2) those in which the nerves supplying the lateral line organs had been cut. After preliminary dissections and experiments it was found that the seventh and tenth cranial nerves could be readily cut by making a small incision just behind the gills.

When a normal mudpuppy was placed in the cage and the wire was set in vibration, three chief types of responses were observed: (1) the rate of respiratory movements of the gills increased and was maintained at a higher level for a brief period; (2) the gills, if moving, stopped; (3) the whole animal might make a sudden movement, as if startled by the sound.

The most satisfactory criterion in observing the behavior of the animals was the rate of gill movements, and this was used as a standard throughout the experiments. Ten normal mudpuppies were each subjected to ten tests in the apparatus and the responses to the vibration of the wire were made ninety-five times. When five mudpuppies in which the nerve connections to the lateral line system had been severed were subjected to similar tests only three doubtful responses resulted in fifty trials. These results indicate that the lateral line of the mudpuppy serves the same function in aquatic amphibians that it does in fishes.

Observations were made which appear to indicate the length of time required for the reestablishment of connections with the lateral line organs after the nerves had been cut. The animals in which the lateral line nerves had been cut were subjected to the tests at intervals of two days. About the eighteenth day from the time of the operation, doubtful responses were noticed. On the twenty-first day the animals responded as they did before the operation. This indicates that the regeneration of the connections had taken place and also gives further support to the view that the lateral line system is of importance in the discrimination of sound vibrations. 


\section{REFERENCES}

Parker, G. H. 1903 Hearing and allied senses in fishes. Bull. U. S. Bureau of Fisheries, 22: 45-64.

1905 The function of the lateral line organs in fishes. Bull. U. S. Bureau of Fisheries, 24: 183-207.

1910 Structure and functions of the ear of the Squeteague. Bull. U. S. Bureau of Fisheries, 28: 1213-1224.

1910 Influence of the eyes, ears, and other allied sense organs on the movements of the dogfish, Mustelus canis (Mitchill). Bull. U. S. Bureau of Fisheries, 29: 43-57.

1911 Effects of explosive sounds, such as those produced by motor boats and guns, upon fishes. U. S. Bureau of Fisheries, Doc. 752 : 1-9.

1912 Sound as a directing influence in the movements of fishes. Bull. U. S. Bureau of Fisheries, 30: 97-104. 